\title{
Environmentally-Relevant Forms of the Prion Protein
}

\author{
Samuel E. Saunders ${ }^{\dagger}$, Jason C. Bartz ${ }^{\ddagger}$, Glenn C. Telling ${ }^{\S}$, and Shannon L. Bartelt-Hunt ${ }^{\dagger,}{ }^{\star}$ \\ tDepartment of Civil Engineering, University of Nebraska-Lincoln, Peter Kiewit Institute, Omaha, \\ Nebraska, United States of America \\ ‡Department of Medical Microbiology and Immunology, Creighton University, Omaha, Nebraska, \\ United States of America \\ §Department of Microbiology, Immunology and Molecular Genetics, Department of Neurology, \\ Sanders Brown Center on Aging, University of Kentucky, Lexington, Kentucky, United States of \\ America
}

\section{Abstract}

Scrapie and chronic wasting disease (CWD) are prion diseases of particular environmental concern as they are horizontally transmissible and can remain infectious after years in the environment. Recent evidence suggests that the $\mathrm{N}$-terminus of $\mathrm{PrP}^{\mathrm{Sc}}$, the infectious conformation of the prion protein, plays an important role in the mechanism of sorption to soil particles. We hypothesize that, in a prion-infected animal carcass, a portion of the $\mathrm{N}$-terminus of $\mathrm{PrP}^{\mathrm{Sc}}$ could be cleaved by proteinases in the brain at ordinary temperatures. Hamster (HY transmissible mink encephalopathy-infected), transgenic mice (CWD-infected), and elk (CWD-infected) brain homogenates were incubated at 22 and $37^{\circ} \mathrm{C}$ for up to 1 month and then analyzed by Western blot using N-terminal and middle region monoclonal anti-PrP antibodies. For all three systems, there was a very faint or undetectable $\mathrm{N}$-terminal PrP signal after 35 days at both temperatures, which indicates that full-length $\mathrm{PrP}^{\mathrm{Sc}}$ might be rare in the brain matter of animal carcasses. Future studies on prion-soil interactions should therefore consider $\mathrm{N}$-terminal-degraded $\mathrm{PrP}^{\mathrm{Sc}}$ in addition to the full-length form. Both mouse and elk CWD PrPSc demonstrated greater resistance to degradation than HY TME PrPSc. This indicates that the transgenic mouse-CWD model is a good surrogate for natural CWD prions, but that other rodent prion models might not accurately represent CWD prion fate in the environment.

\section{Introduction}

Prion diseases, also called transmissible spongiform encephalopathies (TSEs), are a group of fatal neurodegenerative diseases that impact a number of mammalian species and include bovine spongiform encephalopathy (BSE or "mad cow" disease); scrapie of sheep and goats; chronic wasting disease (CWD) of deer, elk, and moose; and Creutzfeldt-Jakob disease in humans (1). Strong evidence suggests that the infectious agent of prion diseases is

*Corresponding author sbartelt2@unl.edu.

Supporting Information Available

Figure S1: UN-infected $\left(\mathrm{PrP}^{\mathrm{C}}\right)$ Hamster Degradation. Figure S2: Total Protein Degradation. Figure S3: Immunoblot band analysis.

This material is available free of charge via the Internet at http://pubs.acs.org. 
comprised of $\operatorname{PrP}^{\mathrm{Sc}}$, an abnormally folded isoform of a normal cellular protein, $\operatorname{PrP}^{\mathrm{c}}$ (1). The misfolded conformation of $\mathrm{PrP}^{\mathrm{Sc}}$ conveys distinct biological and physicochemical properties to $\mathrm{PrP}^{\mathrm{Sc}}$, including resistance to proteolysis, increased hydrophobicity (and thus, decreased solubility in aqueous solvents), and a propensity for aggregation (1). The amino acid sequence of $\mathrm{PrP}$ is species specific, and $\operatorname{PrP}^{\mathrm{Sc}}$ conformation is strain dependent (2-4).

It is known that prions are long-lived in the environment and unusually resistant to most inactivation treatments for conventional pathogens $(5,6)$. Scrapie and CWD are of particular environmental concern as they are horizontally transmissible and can remain infectious after years in the environment (7-10). The scrapie agent remained infectious after burial in garden soil for 3 years (11) and may have persisted for 16 years in a sheephouse (12). The CWD agent was recently identified in saliva and blood of CWD-infected deer, although the brain contains higher levels of infectivity (13). It has been shown that prions are infectious via the nasal cavity (14), and recent bioassays have suggested that prions sorbed to soil particles remain infectious through oral consumption $(15,16)$. Based on these findings, it is clear that prions pose a significant environmental concern.

Two recent studies suggest the potential for environmental degradation of $\mathrm{PrP}^{\mathrm{Sc}}$. Scrapieinfected sheep tissues placed in a compost pile contained no detectable $\mathrm{PrPS}^{\mathrm{Sc}}$ after 108-148 days (17). Similarly, $\mathrm{PrP}^{\mathrm{Sc}}$ was shown to be degraded in soil below lamb carcasses in a field burial site (18). The degradation was correlated to an increase in proteolytic activity and substrate induced respiration. It is important to note that $\mathrm{PrP}^{\mathrm{Sc}}$ degradation was demonstrated by Western blot in both studies, and infectivity was not specifically quantified.

Recent evidence suggests that the $\mathrm{N}$-terminus of the prion protein plays an important role in the mechanism of sorption to soil particles (19-21). Both full-length and N-terminally truncated $\mathrm{PrP}^{\mathrm{c}}$ and $\mathrm{PrP}^{\mathrm{Sc}}$ have been found in vivo (22-26). Because the $\mathrm{N}$-terminal is vulnerable to cleavage (4), N-terminal degradation may occur postmortem. Thus, a truncated form of $\mathrm{PrP}^{\mathrm{Sc}}$ might be prevalent in the environment. The existence of an $\mathrm{N}$-terminal truncated form of $\mathrm{PrP}^{\mathrm{Sc}}$ would directly impact studies of prion fate and transport in the environment. We hypothesize that in a TSE-infected animal carcass, the $\mathrm{N}$-terminal could be cleaved by proteinases in the brain at ordinary temperatures and within an environmentally relevant time period. This paper presents the results of assays simulating environmentally relevant degradation of the prion protein. Brain homogenates were incubated at 22 and 37 ${ }^{\circ} \mathrm{C}$ for up to 1 month and then analyzed for the presence of PrP by Western blot using Nterminal and middle region anti-PrP antibodies. The isoelectric point and aggregation state of $\mathrm{PrPSc}^{\mathrm{Sc}}$ has been shown to vary with $\mathrm{pH}$, particularly from $\mathrm{pH} 4$ to 7 (27), and because enzymatic activity can also vary with $\mathrm{pH}$, we conducted assays using homogenate at $\mathrm{pH} 4$, 7 , and 10 to determine any differences in degradation due to $\mathrm{pH}$.

An accurate in vitro model for evaluation of prion fate in the environment has not yet been established. Studies to date have used rodent models (hamster and murine brain homogenates infected with various prion strains) $(15,16,20,27)$ or recombinant protein models $(18,19,21,28,29)$. To our knowledge, no published studies have directly investigated CWD prion fate in the environment. We hypothesize that conformational and 
amino acid sequence differences between strains and species will impact environmental behavior.

To assess whether a rodent prion model is an acceptable surrogate for the investigation of CWD fate in the environment, this research compares $\mathrm{PrP}^{\mathrm{Sc}}$ degradation in the brain tissue of three representative systems: HY TME infected hamsters, elk CWD-infected transgenic mice expressing elk $\operatorname{PrP}^{\mathrm{c}}(30)$, and CWD-infected elk. For all three systems, there was a very faint or undetectable $\mathrm{N}$-terminal PrP signal after 35 days at both temperatures, which indicates that $\mathrm{N}$-terminal-degraded $\mathrm{PrP}^{\mathrm{Sc}}$ will exist in the environment, and indeed, fulllength $\mathrm{PrP}^{\mathrm{Sc}}$ might be rare in the brain matter of animal carcasses. Future studies on prionsoil interactions should, therefore, consider $\mathrm{N}$-terminal-degraded $\mathrm{PrP}^{\mathrm{Sc}}$ in addition to the full-length form. Interestingly, both mouse and elk CWD $\mathrm{PrP}^{\mathrm{Sc}}$ demonstrated greater resistance to degradation than HY TME PrPSc. This indicates that the transgenic mouseCWD model is a good surrogate for natural CWD prions, but that other rodent prion models might not accurately represent CWD prion fate in the environment.

\section{Materials and Methods}

\section{PrP Sources}

Experiments were conducted using uninfected and HY TME (hyper strain of transmissible mink encephalopathy) infected hamster brain homogenate, transgenic mouse brain homogenate, and CWD-infected elk brain homogenate. All procedures involving animals were done in accordance with the Guide for the Care and Use of Laboratory Animals (31). Syrian hamsters were intracerebrally inoculated with the HY TME agent and sacrificed at terminal disease as described elsewhere (32). $\operatorname{Tg}(\mathrm{CerPrP}) 1536^{+/-}$mice were intracerebrally inoculated with CWD prions from the brain of an infected elk and sacrificed at terminal disease as described elsewhere (30). The exact collection circumstances of the elk brain were unknown, but zero-hour control immunoblot signals were strong when detected with both antibodies used (see Figure 3 below). Infected and uninfected hamster brains, infected mouse brains and CWD-infected elk brain were homogenized to 10\% (w/v) in Dulbecco's phosphate-buffered saline (DPBS) without $\mathrm{Ca}^{2+}$ or $\mathrm{Mg}^{2+}$ (Mediatech, Herndon, VA) using a Tenbroeck tissue grinder (Kontes, Vineland, $\mathrm{NJ}$ ) dedicated to a specific strain. $\mathrm{pH}$ adjustments were made with hydrochloric acid $(\mathrm{HCl})$ and sodium hydroxide $(\mathrm{NaOH})$ and measured using $\mathrm{pH}$ strips.

\section{Degradation Assays}

Three replicates of each brain homogenate sample were placed in $0.2 \mathrm{~mL}$ PCR tubes (Fisher Scientific, Pittsburgh, PA). To prevent evaporation, the tubes were sealed with parafilm and placed in sealed bags containing a towel saturated with deionized water to maintain approximately $100 \%$ relative humidity. Tubes were weighed before and after incubation to ensure no evaporative losses occurred. Measured differences in tube weight before and after incubation were no more than $0.0005 \mathrm{~g}$ or $0.2 \%$. The sealed bags were incubated at $37 \pm 2$ ${ }^{\circ} \mathrm{C}$ or at $22 \pm 2{ }^{\circ} \mathrm{C}$. Samples were removed after $0 \mathrm{~h}$ (control), $6 \mathrm{~h}, 1 \mathrm{~d}, 2 \mathrm{~d}, 7 \mathrm{~d}$, and $35 \mathrm{~d}$ and stored at $-80^{\circ} \mathrm{C}$ until analysis. 


\section{Western Blotting}

Samples were thawed and vortexed thoroughly. For proteinase K(PK) treatment, sample aliquots were incubated at $37{ }^{\circ} \mathrm{C}$ under constant agitation for $1 \mathrm{~h}$ with $25 \mu \mathrm{g}$ PK per ml of sample (Roche Diagnostics Corporation, Indianapolis, IN). PK digestion was stopped by boiling in SDS-PAGE sample buffer. Western blot analysis was performed as described previously (32). Briefly, sample and control aliquots $(2.5 \mu \mathrm{L})$ were boiled in SDS-PAGE sample buffer at $100{ }^{\circ} \mathrm{C}$ for 10 min, separated on $12.5 \%$ acrylamide gels under reducing conditions, and transferred to polyvinyl difluoride (PVDF) membranes. Hamster samples were immunoblotted with mAb 3F4 (Chemicon, Temecula, CA, 1:10 000 dilution), mAb 8B4 (Santa Cruz Biotechnology, Santa Cruz, CA, 1:1000) or mAb 5B2 (Santa Cruz Biotechnology, 1:1000). 3F4 reacts with residues 110-113 (MKHM) in hamster PrP. 8B4 reacts with residues 37-39 (RYP) in murine PrP, and 5B2 reacts with the 8B4 epitope plus residues 48-50 (RYP) (33). Elk samples were immunoblotted with L42 (R-Biopharm, Marshall, MI, 1:1000) or 5B2 (1:1000). L42 reacts with residues 145-163 in ovine PrP (34). Blots were developed with Pierce Supersignal West Femto maximum-sensitivity substrate, according to the manufacturer's instructions (Pierce, Rockford, IL), and imaged on a Kodak 2000R imaging station (Kodak, Rochester, NY).

\section{Quantitative Analysis}

Blot images were analyzed using Kodak 1D 4.0 software (Kodak, Rochester, NY), which output the net intensity of each blot (total darkness minus background). For each Western blot, the net intensities of four or five time-point replicates (one to two aliquots from each tube) were normalized to three replicate zero-hour controls. All samples were tested for significant difference against the zero-hour controls using a Student's $t$ test for two sample means with unequal variances (SAS, SAS Institute Inc., Cary, NC). pH data were analyzed for significance using a type 3 Test of Fixed Effects. Two-tail $P$ values less than 0.05 were considered significant.

\section{Results}

Brain homogenates from animals infected or not infected with prion diseases were incubated at 22 and $37{ }^{\circ} \mathrm{C}$ for up to 35 days. After incubation, samples and zero hour controls were analyzed with SDS-PAGE and Western blotting using monoclonal antibodies with epitopes on the $\mathrm{N}$-terminal and middle regions of the prion protein (Figure 1). The mAb 5B2 was used interchangeably with $\mathrm{mAb} 8 \mathrm{~B} 4$ for $\mathrm{N}$-terminal detection, since it has a similar epitope (Figure 1B) and is also lost with proteinase $\mathrm{K}$ digestion (data not shown). Loss of the $\mathrm{N}$ terminal decreases the molecular weight of PrP; thus, $\mathrm{PK}$ treatment causes a redistribution in the banding pattern of PrP in the mAb 3F4 blot (Figure 1A, lane 4). The mAb 3F4 was used for hamster samples, but did not recognize elk PrP. Therefore, mAb L42, which has a similar middle-region epitope as 3F4 (Figure 1B) and is similarly retained after PK digestion (data not shown), was used for elk and transgenic mouse samples. Sample PrP signals ( $n=4$ or 5) were quantified and normalized to zero hour controls $(n=3)$ of the same tissue and antibody. 


\section{HY TME PrPSc Degradation}

HY TME is a robust prion strain with a higher resistance to PK digestion compared with other rodent strains (4). After incubation, brain homogenate from hamsters infected with the HY TME agent showed decreasing PrP abundance with respect to time for both middle region $(\mathrm{mAb} 3 \mathrm{~F} 4)$ and $\mathrm{N}$-terminal region (8B4) antibodies at all $\mathrm{pH}$ levels and at both temperatures. Significant N-terminal PrP degradation $(p<0.05)$, corresponding to a loss of the 8B4 PrP N-terminal epitope, occurred within 1 week at both temperatures and all $\mathrm{pH}$ levels (Figure 2A and B). No 8B4 signal was detected after 7 days at $22{ }^{\circ} \mathrm{C}$ for $\mathrm{pH} 7$ and after 35 days for $\mathrm{pH} 4$ and 10 (Figure 2A, lanes 5, 9, and 14). 8B4 signal was lost after 7 days at $37^{\circ} \mathrm{C}$ for all $\mathrm{pH}$ levels (Figure 2B, lanes 4, 9, and 13). Therefore, full-length PrP was not detected in any sample after incubation for 35 days at 22 or $37^{\circ} \mathrm{C}$.

Significant middle region $\operatorname{PrP}$ degradation $(p<0.05)$, as indicated by the loss of 3F4 immunoreactivity, occurred within 7 days at $22{ }^{\circ} \mathrm{C}$ (Figure $2 \mathrm{C}$ ) and within $24 \mathrm{~h}$ at $37{ }^{\circ} \mathrm{C}$ (Figure 2D) for all $\mathrm{pH}$ levels. After 35 days, the sample 3F4 signal intensities were less than $20 \%$ of the zero hour controls for $22{ }^{\circ} \mathrm{C}$ incubation and less than $5 \%$ for $37^{\circ} \mathrm{C}$. Thus, not only was the N-terminal region of PrP lost, but most of the PK-resistant core of PrP was degraded after 35 days incubation.

No clear differences in degradation due to $\mathrm{pH}$ were observed. A quarter of the samples (4 of 16) had significant difference $(p<0.05)$ in degradation between $\mathrm{pH}$ levels, but these differences did not correspond with consistent temperatures, time points, or antibodies. In addition, no single set of comparisons between $\mathrm{pH}$ levels (e.g., $\mathrm{pH} 4 \mathrm{vs} \mathrm{pH} 10$ ) yielded more differences than any other. Increasing temperature from 22 to $37^{\circ} \mathrm{C}$ did increase the degradation rate for 24 out of 27 time/antibody points ( 14 of the 24 were statistically significant with $p<0.05$ ).

Uninfected (UN) brain homogenate was subjected to the same degradation assay to determine the behavior of $\operatorname{PrP}^{\mathrm{c}}$. Significant degradation $(p<0.05)$ of the N-terminal 5B2 epitope occurred within $48 \mathrm{~h}$ (Supporting Information (SI) Figure S1A and B, lanes 2, 5, and 8). The 5B2 epitope was not detectable after 35 days for all $\mathrm{pH}$ levels and temperatures (SI Figure $\mathrm{S} 1 \mathrm{~A}$ and $\mathrm{B}$, lanes 3,6 , and 9 ), except $\mathrm{pH} 4,22{ }^{\circ} \mathrm{C}(9 \%$ normalized intensity, SI Figure S1A, lane 3). Significant loss of the $3 \mathrm{~F} 4$ epitope occurred within 7 days for all $\mathrm{pH}$ levels at both $22{ }^{\circ} \mathrm{C}$ (SI Figure S1C, lanes 3, 7, and 11) and $37^{\circ} \mathrm{C}$ (SI Figure S1D). The 3F4 normalized signal intensities were 2,14 , and $1 \%$ for $\mathrm{pH} 4,7$, and 10 , respectively, after 35 days incubation at $22{ }^{\circ} \mathrm{C}$ (SI Figure S1C, lanes 4, 8, and 12). The 3F4 epitope was undetectable for all $\mathrm{pH}$ levels after 35 days incubation at $37^{\circ} \mathrm{C}$ (SI Figure S1D, lanes 4, 8, and 12). As with HY TME PrP, no clear differences in $\mathrm{PrP}^{\mathrm{c}}$ degradation were observed between $\mathrm{pH}$ levels. While 6 out of 10 samples had some significant difference $(p<0.05)$ in degradation between $\mathrm{pH}$ levels, no one comparison between $\mathrm{pH}$ 4, 7, and 10 had more differences than the others. Similar to HY TME PrP, increasing temperature from 22 to 37 ${ }^{\circ} \mathrm{C}$ increased $\operatorname{PrP}^{\mathrm{c}}$ degradation for 14 out of 15 time/antibody points (13 of which were statistically significant with $p<0.05$ ).

HY TME samples were subjected to SDS-PAGE and then stained with coomassie blue to quantify total protein degradation. The decrease in PrP abundance was mirrored by a 
decrease in total protein only at $37^{\circ} \mathrm{C}$ (SI Figure S2). Total protein remained constant throughout the 35 day experiment at $22^{\circ} \mathrm{C}$ (SI Figure S2, lane 3), while it was significantly decreased after 1 week at $37{ }^{\circ} \mathrm{C}$ (SI Figure S2, lane 4). After 35 days at $37{ }^{\circ} \mathrm{C}$, the sample stain had a normalized intensity of $18 \%$, indicating that over $80 \%$ of the total protein in the homogenate was degraded.

\section{CWD PrPSc Degradation}

To compare the HY TME hamster $\operatorname{PrP}^{\mathrm{Sc}}$ degradation behavior to a natural prion disease, CWD-infected elk brain was subjected to the same degradation assay at $\mathrm{pH}$ 7. Significant loss of the N-terminal 5B2 epitope Western blot signal occurred within $48 \mathrm{~h}$ incubation at both $22^{\circ} \mathrm{C}$ (Figure $3 \mathrm{~A}$, lane 3 ) and $37^{\circ} \mathrm{C}$ (Figure $3 \mathrm{~A}$, lane 8). Similar to HY TME, there was no detectable $\mathrm{N}$-terminal 5B2 epitope after 35 days at $37^{\circ} \mathrm{C}$ (Figure $3 \mathrm{~A}$, lane 10), although a faint signal ( $6 \%$ normalized intensity) remained after 35 days at $22^{\circ} \mathrm{C}$ (Figure $3 \mathrm{~A}$ lane 5). Therefore, almost all of the starting full-length PrP population in the elk brain homogenate was $\mathrm{N}$-terminal truncated after 35 days incubation.

The PrP middle region antibody (mAb L42) epitope of elk CWD PrPSc did not decrease with time as with the HY TME and UN-infected hamster brain homogenates. After 35 days at $22{ }^{\circ} \mathrm{C}$ (Figure 3B, lane 5), the signal was reduced ( $80 \%$ normalized intensity), but this reduction was not significant $\left(p<0.05\right.$ ). Moreover, after 35 days incubation at $37^{\circ} \mathrm{C}$ (Figure $3 \mathrm{~B}$, lane 10), the sample intensity was equal to the control intensity, which agrees with a previous result by Traintis et al. (35). Unlike the HY TME and UN-infected assays, there was no clear difference in degradation between 22 and $37^{\circ} \mathrm{C}$. Six out of $1022^{\circ} \mathrm{C}$ samples were more degraded than the corresponding $37^{\circ} \mathrm{C}$ samples, and only one data point was significantly different $(p<0.05)$ between temperatures (the 1 day 5B2).

Transgenic mice, referred to as $\operatorname{Tg}(\mathrm{CerPrP}) 1536^{+/-}$, are susceptible to CWD prions from deer and elk (30). Brain extracts from diseased $\operatorname{Tg}(\mathrm{CerPrP}) 1536^{+/-}$infected with CWD-elk prions, were tested at $\mathrm{pH} 7$ to determine whether this was an accurate model for environmentally relevant degradation of natural CWD PrPSc. The $\operatorname{Tg}(\mathrm{Cer}-\mathrm{PrP}) 1536^{+/-}$derived CWD $\mathrm{PrP}^{\mathrm{Sc}}$ lost the N-terminal 5B2 epitope by 33 days of incubation at 22 and 37 ${ }^{\circ} \mathrm{C}$ (Figure 3C, lanes 5 and 10). A significant reduction in the abundance of the $\mathrm{N}$-terminal 5B2 epitope ( $p<0.05$ ) occurred within $48 \mathrm{~h}$ at both temperatures (Figure 3C, lanes 3 and 8 ). There was no significant reduction in the presence of the $\mathrm{L} 42$ epitope of $\mathrm{PrP}^{\mathrm{Sc}}$ from $\operatorname{Tg}(\mathrm{CerPrP})-1536^{+/-}$-derived CWD after 33 days incubation (Figure 3D, lanes 5 and 10), similar to what was observed in CWD-infected elk samples (Figure 3B). Results for 22 and $37^{\circ} \mathrm{C}$ were quantitatively similar. Half of the $22^{\circ} \mathrm{C}$ samples were more degraded than the corresponding $37^{\circ} \mathrm{C}$ samples, and only two data points were significantly different ( $p<$ 0.05 ) between temperatures (5B2 at $2 \mathrm{~d}$ and L42 at $35 \mathrm{~d}$ ).

\section{Discussion}

A redistribution in the banding pattern of $\operatorname{PrP}$, as detected by the core-region antibody (3F4 and L42), was seen over time in both HY TME and CWD samples (SI Figure S3). This change was more pronounced at $37{ }^{\circ} \mathrm{C}$ incubation but also occurred at $22{ }^{\circ} \mathrm{C}$. Since a similar shift is not seen with the $\mathrm{N}$-terminal epitope antibodies, the shift most likely corresponds to 
the loss of the N-terminus region of PrP. It is possible that changes in glycosylation during incubation are also partly responsible. Differential degradation of the various forms of PrP could have also occurred. However, antibodies can have differing affinities for each glycoform of PrP, as demonstrated in this study (compare Figure 3A lane 1 and Figure 3B lane 1). Thus, changes in PrP glycosylation during these experiments are difficult to assess and further investigation would be required to determine any effect of glycosylation on degradation behavior.

$\mathrm{pH}$ can affect enzyme activity and the aggregation of $\mathrm{PrP}^{\mathrm{Sc}}$; however, in this study, there was no clear effect on hamster PrP degradation due to changes in $\mathrm{pH}$. Loss of the PrP Nterminus occurred at all $\mathrm{pH}$ levels, and core PrP degradation was similar as well. It is possible that the activity of the enzymes responsible for PrP degradation did not vary substantially over the $\mathrm{pH}$ range tested, but these enzymes would need to be identified to confirm this. Since we did not directly measure $\mathrm{PrP}^{\mathrm{Sc}}$ aggregation, it remains unclear what influence, if any, it has on $\mathrm{PrP}^{\mathrm{Sc}}$ resistance to environmental degradation.

The effect of temperature in this degradation assay differed between hamster and CWD samples. Increasing temperature from 22 to $37^{\circ} \mathrm{C}$ did increase the degradation rate for $\mathrm{HY}$ TME and $\mathrm{PrP}^{\mathrm{c}}$ in hamster brain. This was presumably due to increased enzymatic activity in the hamster homogenates at $37{ }^{\circ} \mathrm{C}$ compared to $22{ }^{\circ} \mathrm{C}$. However, CWD PrP degradation in both elk and mouse brain did not differ significantly between the 22 and $37^{\circ} \mathrm{C}$ samples. Interestingly, total protein in the HY TME samples remained steady throughout the 35 day experiment at $22{ }^{\circ} \mathrm{C}$, while it was significantly decreased after 1 week at $37{ }^{\circ} \mathrm{C}$. This suggests that the enzymes which degrade PrP are active at both temperatures, while the majority of proteases in the homogenate are only active at $37^{\circ} \mathrm{C}$.

In this study, we simulated a natural scenario in which a TSE-infected animal dies and remains at ordinary physiological and ambient temperatures. Our results indicate that under these conditions, the N-terminus of brain derived $\mathrm{PrPSc}^{\mathrm{Sc}}$ is lost after 7-35 days. This could be due to natural proteases or other compounds existing in the brain prior to death. It is important to note that our results do not measure infectivity. Loss of the proteinase $\mathrm{K}$ (PK) sensitive $\mathrm{N}$-terminus of $\mathrm{PrP}^{\mathrm{Sc}}$ does not reduce infectivity in rodent-adapted prion diseases (4); however, this has not to our knowledge been demonstrated with the CWD agent. A decrease in abundance or a complete failure to detect $\mathrm{PrP}^{\mathrm{Sc}}$ by Western blot using anti-PrP antibodies with epitopes between the C-terminal and the PK cleavage site does not always correlate with a decrease in infectivity (36-38). Any differences in infectivity or disease incubation time resulting from the degradation assay would have to be confirmed by animal bioassay. Nonetheless, this study raises a number of important issues.

Both $\mathrm{PrP}^{\mathrm{c}}$ and $\mathrm{PrP}^{\mathrm{Sc}}$ exist in vivo as a highly heterogeneous population with both full-length and N-terminal truncated forms (22-26). Thus, it is not surprising that our results indicate $\mathrm{PrP}^{\mathrm{Sc}}$ lacking the $\mathrm{N}$-terminal peptide will exist in the environment. However, due to the near-complete loss of the $\mathrm{N}$-terminus of $\mathrm{PrP}^{\mathrm{Sc}}$ after incubation, our results suggest that fulllength $\mathrm{PrP}^{\mathrm{Sc}}$ might be rare in the brain matter of animal carcasses greater than 1 week old. The environmental behavior of $\operatorname{PrP}^{\mathrm{Sc}}$ lacking the $\mathrm{N}$-terminal region could be markedly different from full-length $\mathrm{PrP}^{\mathrm{Sc}}$. Others have speculated that the N-terminal portion of $\mathrm{PrP}^{\mathrm{Sc}}$ 
may play a role in sorption to soils $(19,20)$. In addition, any changes in glycosylation that are induced by incubation, as suggested by the changes in immunoblot band intensities, could also affect sorption or longevity in the environment. Current understanding of prionsoil interactions is still limited. Future work should consider prion-soil interactions using Nterminal-degraded prions in addition to full-length forms.

Our results suggest that rodent-adapted prions may not recapitulate CWD. While both hamster and CWD-elk $\mathrm{PrP}^{\mathrm{Sc}}$ eventually lost the $\mathrm{N}$-terminus during the incubation assay, the elk $\mathrm{PrP}^{\mathrm{Sc}}$ demonstrated more resistance to degradation of its $\mathrm{C}$-terminal core than the hamster $\operatorname{PrP}^{\mathrm{Sc}}$. However, it can not be ruled out that some of the species-specific differences in $\mathrm{PrP}^{\mathrm{Sc}}$ degradation were due to differences in the binding properties of the antibodies used to detect $\mathrm{PrP}^{\mathrm{Sc}}$ from the two species. Thus, conclusions drawn regarding the condition and behavior of prions in the environment based on experiments using conventional rodent models may not be a fully accurate representation of CWD prion behavior based on $\operatorname{PrP}^{\mathrm{Sc}}$ degradation and/or detection properties. Our results suggest a more appropriate model, in the absence of natural tissue, would be transgenic mice expressing cervid PrP infected with CWD prions. In addition, it is clear from these experiments that the brain homogenate matrix can change the properties of $\mathrm{PrP}^{\mathrm{Sc}}$ under natural conditions. Recombinant $\mathrm{PrP}$ or $\mathrm{PrP}^{\mathrm{Sc}}$ purified with detergent extraction and thereby artificially aggregated might not be appropriate for some environmental investigations as they are not subjected to this natural matrix, nor do they represent the PrP population heterogeneity in vivo.

More research will be required to determine the biochemical details of the PrP degradation this study demonstrated, including the mechanisms of why CWD $\mathrm{PrP}^{\mathrm{Sc}}$ is more resistant to degradation than HY TME. It is possible that the hamster brain contains enzymes which are better equipped to degrade PrP. However, CWD behavior was the same in both elk and mouse brain homogenate. Therefore, it is more likely due to conformational differences between elk CWD and HY TME PrP ${ }^{S c}$ which make the HY TME PrP more susceptible to natural cleavage and destruction.

\section{Supplementary Material}

Refer to Web version on PubMed Central for supplementary material.

\section{Acknowledgments}

We thank Ronald Shikiya and Jacob Ayers for technical assistance and Ken Clinkenbeard for the CWD-elk brain. We also thank Stephen Kachman for performing statistical analyses. This research was supported in part by the National Center for Research Resources (PZORR0115635-6 and CO6RR17417-01 - JCB) and by the University of Nebraska-Lincoln Research Council (SLB).

\section{Literature Cited}

1. Prusiner SB. The prion diseases. Brain Path. 1998; 8:499-513. [PubMed: 9669700]

2. Safar J, Willie H, Itri V, Groth D, Serban H, Torchia M, Cohen FE, Prusiner SB. Eight prion strains have $\mathrm{PrP}^{\mathrm{Sc}}$ molecules with different conformations. Nat. Med. 1998; 4:1157-1165. [PubMed: 9771749]

3. Bessen RA, Marsh RF. Biochemical and physical-properties of the prion protein from 2 strains of the transmissible mink encephalopathy agent. J. Virol. 1992; 66:2096-2101. [PubMed: 1347795] 
4. Bessen RA, Marsh RF. Distinct PrP properties suggest the molecular basis of strain variation in transmissible mink encephalopathy. J. Virol. 1994; 68:7859-7868. [PubMed: 7966576]

5. Brown P, Rau EH, Lemieux P, Johnson BK, Bacote AE, Gajdusek DC. Infectivity studies of both ash and air emissions from simulated incineration of scrapie-contaminated tissues. Environ. Sci. Technol. 2004; 38:6155-6160. [PubMed: 15575075]

6. Taylor DM. Inactivation of transmissible degenerative encephalopathy agents: A review. Vet. J. 2000; 159:10-17. [PubMed: 10640408]

7. Greig JR. Scrapie: Observation on the transmission of the disease by mediate contact. Vet. J. 1940; 96:203-206.

8. Hadlow WJ, Kennedy RC, Race RE. Natural infection of suffolk sheep with scrapie virus. J. Infect. Dis. 1982; 146:657-664. [PubMed: 6813384]

9. Miller MW, Williams ES. Horizontal prion transmission in mule deer. Nature. 2003; 425:35-36. [PubMed: 12955129]

10. Miller MW, Williams ES, Hobbs NT, Wolfe LL. Environmental source of prion transmission in mule deer. Emerging Infect. Dis. 2004; 10:1003-1006. [PubMed: 15207049]

11. Brown P, Gajdusek DC. Survival of scrapie virus after 3 year's interment. Lancet. 1991; 337:269_ 270. [PubMed: 1671114]

12. Georgsson G, Sigurdarson S, Brown P. Infectious agent of sheep scrapie may persist in the environment for at least 16 years. J. Gen. Virol. 2006; 87:3737-3740. [PubMed: 17098992]

13. Mathiason CK, Powers JG, Dahmes SJ, Osborn DA, Miller KV, Warren RJ, Mason GL, Hays SA, Hayes-Klug J, Seelig DM, Wild MA, Wolfe LL, Spraker TR, Miller MW, Sigurdson CJ, Telling GC, Hoover EA. Infectious prions in the saliva and blood of deer with chronic wasting disease. Science. 2006; 314:133-135. [PubMed: 17023660]

14. Kincaid AE, Bartz JC. The nasal cavity is a route for prion infection in hamsters. J. Virol. 2007; 81:4482-4491. [PubMed: 17301140]

15. Johnson CJ, Pedersen JA, Chappell RJ, McKenzie D, Aiken JM. Oral transmissibility of prion disease is enhanced by binding of soil particles. PLoS Pathog. 2007; 3:e93. [PubMed: 17616973]

16. Seidel B, Thomzig A, Buschmann A, Groschup MH, Peters R, Beekes M, Terytze K. Scrapie agent (strain 263K) can transmit disease via the oral route after persistence in soil over years. PLoS ONE. 2007; 3:e435. [PubMed: 17502917]

17. Huang H, Spencer JL, Soutryine A, Guan J, Rendulich J, Balachandran A. Evidence of degradation of abnormal prion protein in tissues from sheep with scrapie during composting. Can. J. Vet. Res. 2007; 71:34-40. [PubMed: 17193880]

18. Rapp D, Potier P, Jocteur-Monrozier L, Richaume A. Prion degradation in soil: Possible role of microbial enzymes stimulated by the decomposition of buried carcasses. Environ. Sci. Technol. 2006; 40:6324-6329. [PubMed: 17120560]

19. Cooke CM, Rodger J, Smith A, Fernie K, Shaw G, Somerville RA. Fate of prions in soil: Detergent extraction of PrP from soils. Environ. Sci. Technol. 2007; 41:811-817. [PubMed: 17328187]

20. Johnson CJ, Phillips KE, Schramm PT, McKenzie D, Aiken JM, Pedersen JA. Prions adhere to soil minerals and remain infectious. PLoS Pathog. 2006; 2:296-302.

21. Rigou P, Rezaei H, Grosclaude J, Staunton S, Quiquampoix H. Fate of prions in soil: Adsorption and extraction by electroelution of recombinant ovine prion protein from montmorillonite and natural soils. Environ. Sci. Technol. 2006; 40:1497-1503. [PubMed: 16568762]

22. González L, Martin S, Begara-McGorum I, Hunter N, Houston F, Simmons M, Jeffrey M. Effects of agent strain and host genotype on PrP accumulation in the brain of sheep naturally and experimentally affected with scrapie. J. Comp. Pathol. 2002; 126:17-29. [PubMed: 11814318]

23. González L, Martin S, Jeffrey M. Distinct profiles of $\operatorname{PrP}^{\mathrm{d}}$ immunoreactivity in the brain of scrapie- and BSR-infected sheep: Implications for differential cell targeting and PrP processing. J. Gen. Virol. 2003; 84:1339-1350. [PubMed: 12692301]

24. Jeffrey M, Martin S, González L. Cell-associated variants of disease-specific prion protein immunolabelling are found in different sources of sheep transmissible spongiform encephalopathy. J. Gen. Virol. 2003; 84:1033-1045. [PubMed: 12655107] 
25. Kuczius T, Grassi J, Karch H, Groschup MH. Binding of N-and C-terminal anti-prion protein antibodies generates distinct phenotypes of cellular prion proteins $\left(\operatorname{PrP}^{\mathrm{c}}\right)$ obtained from human, sheep, cattle, and mouse. FEBS J. 2007; 274:1492-1502. [PubMed: 17302739]

26. Pan T, Wong PK, Chang BG, Li CY, Li RL, Kang SC, Wisniewski T, Sy MS. Biochemical fingerprints of prion infection: Accumulations of aberrant full-length and $\mathrm{N}$-terminally truncated PrP species are common features in mouse prion disease. J. Virol. 2005; 79:934-943. [PubMed: 15613322]

27. Ma X, Benson CH, McKenzie D, Aiken JM, Pedersen JA. Adsorption of pathogenic prion protein to quartz sand. Environ. Sci. Technol. 2007; 41:2324-2330. [PubMed: 17438782]

28. Cooke CM, Shaw G. Fate of prions in soil: Longevity and migration of recPrP in soil columns. Soil Biol. Biochem. 2007; 39:1181-1191.

29. Pucci A, D'Acqui LP, Calamai L. Fate of prions in soil: Interactions of recPrP with organic matter of soil aggregates as revealed by LTA-PAS. Environ. Sci. Technol. 2008; 42:728-733. [PubMed: 18323094]

30. Browning SR, Mason GL, Seward T, Green M, Eliason GAJ, Mathiason C, Miller MW, Williams ES, Hoover E, Telling GC. Transmission of prions from mule deer and elk with chronic wasting disease to transgenic mice expressing cervid PrP. J. Virol. 2004; 78:13345-13350. [PubMed: 15542685]

31. National Research Council. Guide for the Care and Use of Laboratory Animals. Washington, DC: National Academy Press; 1996.

32. Bartz JC, Kramer ML, Sheehan MH, Hutter JAL, Ayers JI, Bessen RA, Kincaid AE. Prion interference is due to a reduction in strain-specific $\mathrm{PrP}^{\mathrm{Sc}}$ levels. J. Virol. 2007; 81:689-697. [PubMed: 17079313]

33. Li R, Liu T, Wong B-S, Pan T, Morillas M, Swietnicki W, O'Rourke K, Gambetti P, Surewicz WK, Sy M-S. Identification of an epitope in the $\mathrm{C}$ terminus of normal prion protein whose expression is modulated by binding events in the N terminus. J. Mol. Biol. 2000; 301:567-573. [PubMed: 10966770]

34. Harmeyer S, Pfaff E, Groschup MH. Synthetic peptide vaccines yield monoclonal antibodies to cellular and pathological prion proteins of ruminants. J. Gen. Virol. 1998; 79:937-945. [PubMed: 9568991]

35. Triantis J, Dennis MM, Salman MD, Gould DH. Effect of time and temperature on PrP $\mathrm{P}^{\mathrm{cwd}}$ immunoreactivity as evidenced by western blot. J. Vet. Diagn. Invest. 2007; 19:389-391. [PubMed: 17609348]

36. Barron RM, Campbell SL, King D, Bellon A, Chapman KE, Williamson RA, Manson JC. High titers of transmissible spongiform encephalopathy infectivity associated with extremely low levels of $\mathrm{PrP}^{\mathrm{Sc}}$ in vivo. J. Biol. Chem. 2007; 282:35878-35886. [PubMed: 17923484]

37. McLeod AH, Murdoch H, Dickinson J, Dennis MJ, Hall GA, Buswell CM, Carr J, Taylor DM, Sutton JM, Raven ND. Proteolytic inactivation of the bovine spongiform encephalopathy agent. Biochem. Biophys. Res. Com. 2004; 317:1165-1170. [PubMed: 15094392]

38. Scherbel C, Pichner R, Groschup MH, Mueller-Hellwig S, Scherer S, Dietrich R, Maertlbauer E, Gareis M. Infectivity of scrapie prion protein $\mathrm{PrP}^{\mathrm{Sc}}$ following in vitro digestion with bovine gastrointestinal microbiota. Zool. Public Health. 2007; 54:185-190. 


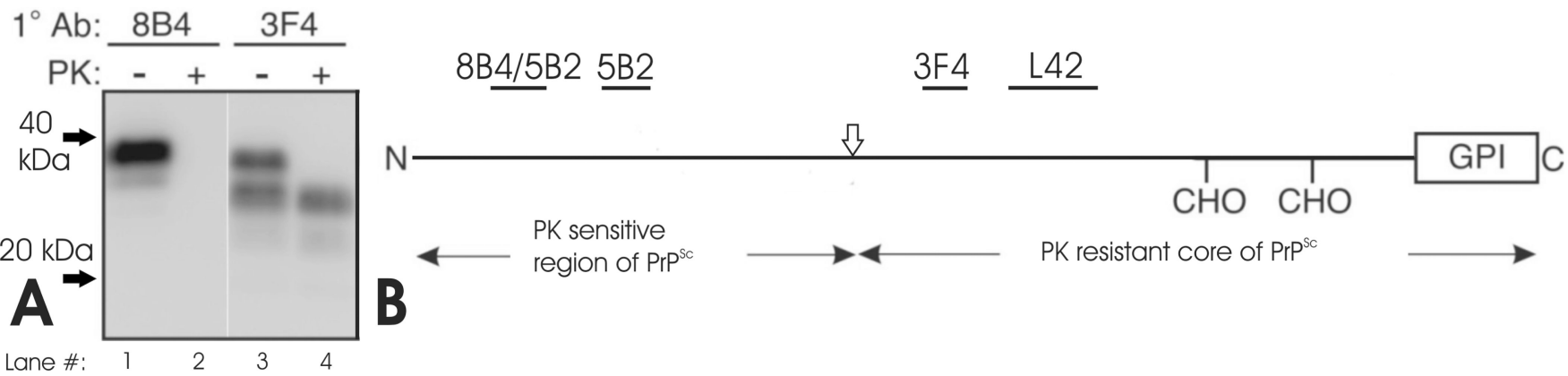

FIGURE 1.

$\mathrm{PrP}^{\mathrm{Sc}}$ Detection Using Various Anti-PrP Antibodies. Panel A: Representative immunoblots of HY TME agent-infected brain homogenate using different antibodies, with $(+)$ or without $(-)$ proteinase $\mathrm{K}(\mathrm{PK})$ treatment. Panel B: A schematic representation of $\mathrm{PrP}^{\mathrm{Sc}}$ indicating the epitope location of each anti-PrP antibody used, the PK cleavage site, the $\mathrm{N}$-linked glycosylations (CHO), and the gylcosylphosphatidylinostiol anchor (GPI). See Materials and Methods for the exact antibody epitopes. 

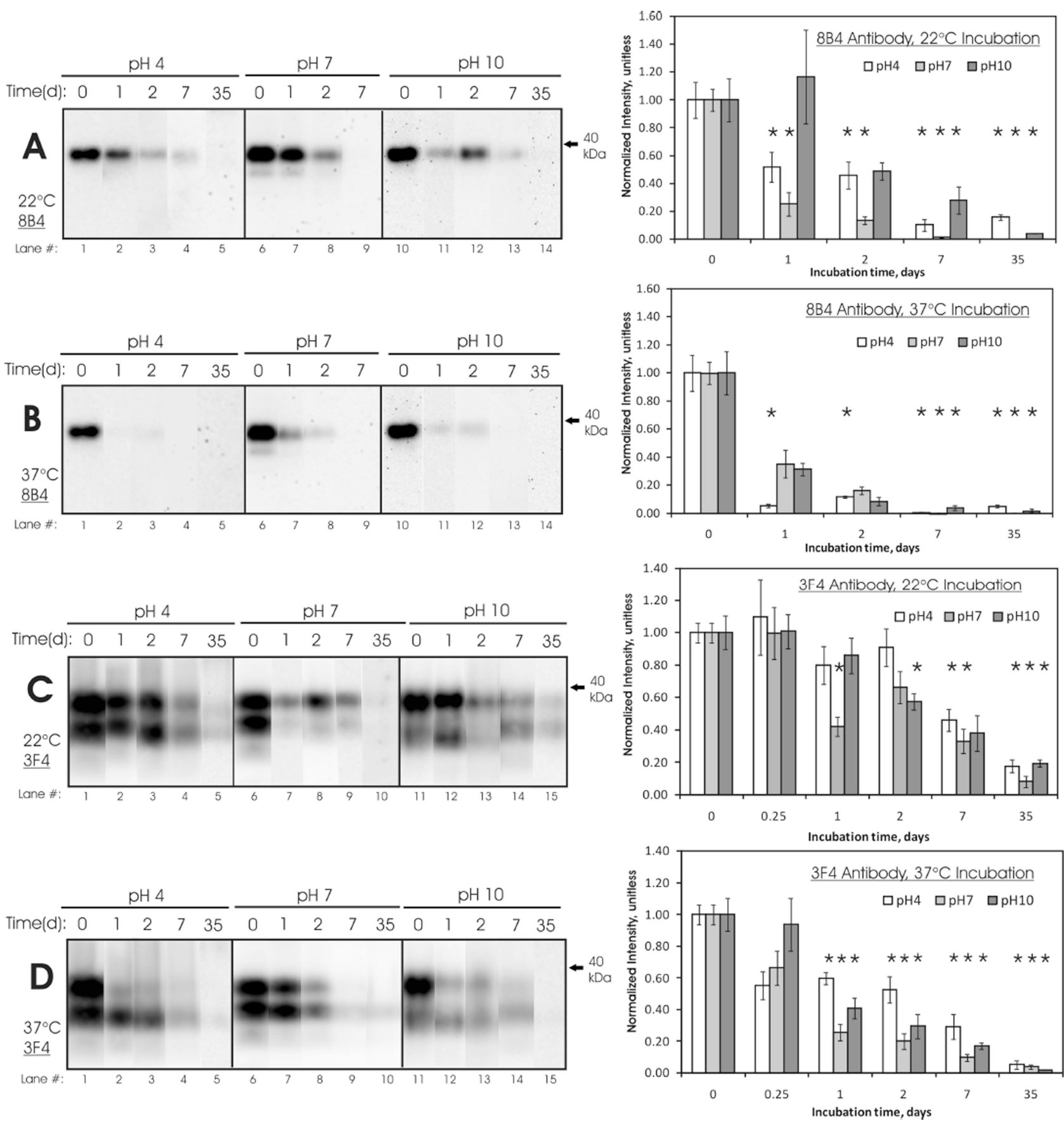

FIGURE 2.

HY TME Degradation. On the left: representative immunoblots of $2.5 \mu \mathrm{L}$ of $10 \% \mathrm{BH}(\mathrm{pH} 4$, 7 , or 10) after incubation for up to 35 days. Samples were not treated with proteinase K. On the right: signal intensities of sample blots $(n=4$ or 5$)$ were normalized against $0 \mathrm{~h}$ controls. * Denotes significance $(p<0.05)$ between the control mean $(t=0)$ and the sample mean. Error bars show \pm 1 standard error of the mean. Panel A: Incubation at $22{ }^{\circ} \mathrm{C}$ detected with mAb 8B4 (N-terminal epitope). Panel B: $37^{\circ} \mathrm{C}$ detected with mAb 8B4. Panel C: $22{ }^{\circ} \mathrm{C}$ detected with mAb 3F4 (middle region epitope). Panel D: $37^{\circ} \mathrm{C}$ detected with mAb 3F4. 

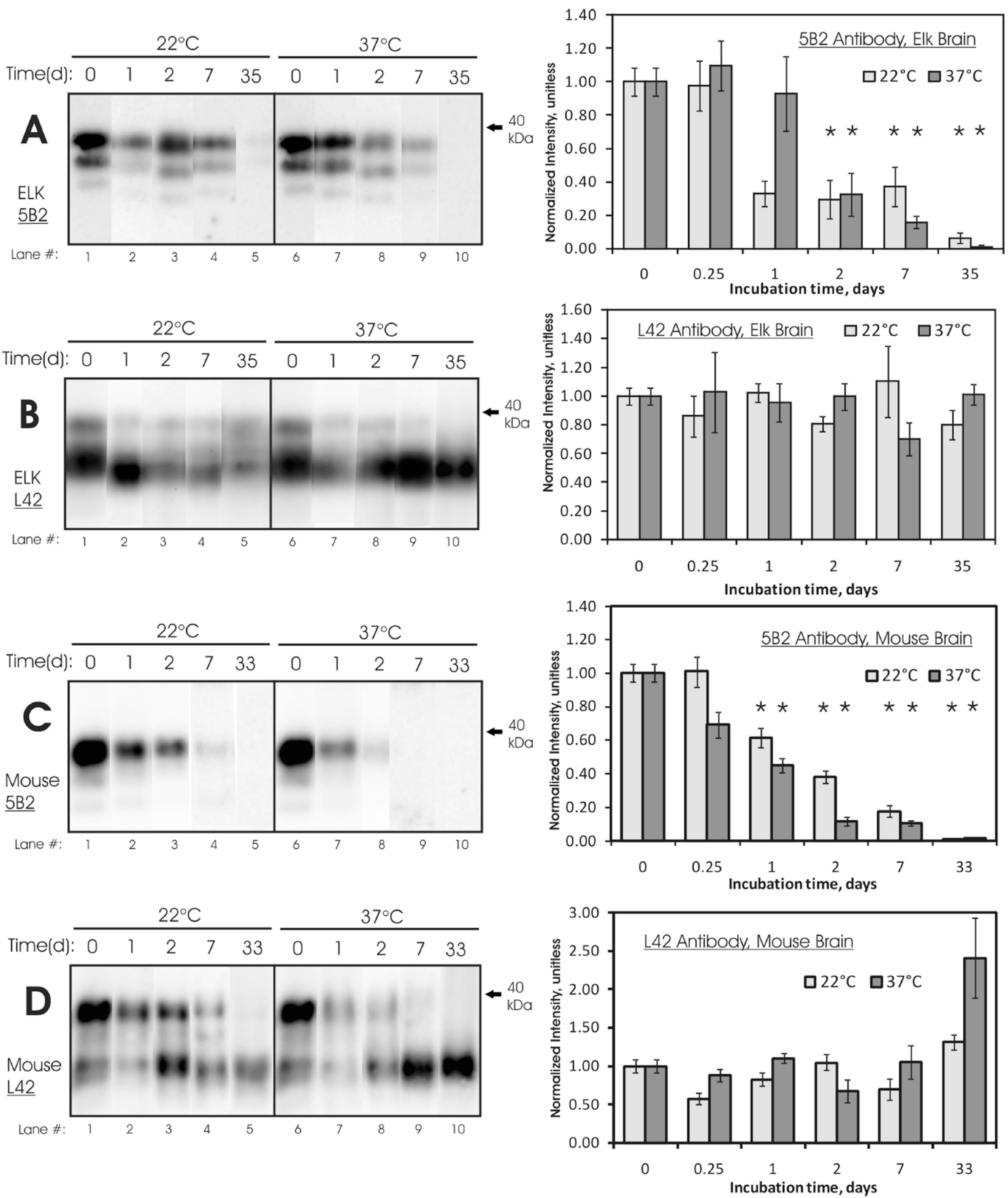

FIGURE 3.

CWD Degradation. On the left: representative immunoblots of $2.5 \mu \mathrm{L}$ of $10 \% \mathrm{BH}(\mathrm{pH} 7)$ after incubation for up to 35 days. Samples were not treated with proteinase K. On the right: signal intensities of sample blots $(n=4$ or 5$)$ were normalized against $0 \mathrm{~h}$ controls. * Denotes significance $(p<0.05)$ between the control mean $(t=0)$ and the sample mean. Error bars show \pm 1 standard error of the mean. Panel A: CWD-infected elk brain homogenate detected with mAb 5B2 (N-terminal epitope). Panel B: CWD-elk detected with mAb L42 (middle region epitope). Panel C: CWD-infected transgenic mouse brain homogenate 
detected with 5B2. Panel D: CWD-mouse detected with L42 (note the different vertical scale). 